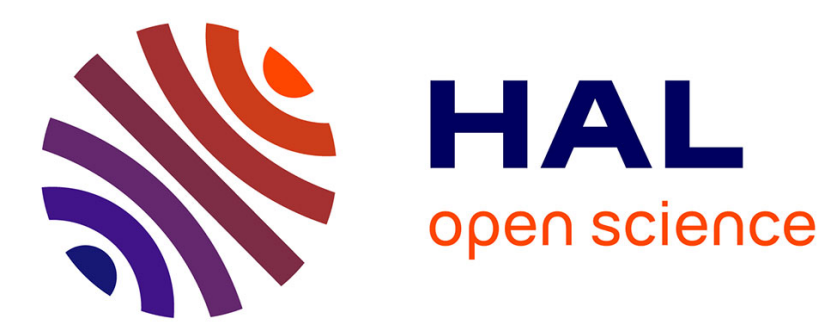

\title{
SINGLE-PROCESS THEORIES OF GRAIN BOUNDARY MIGRATION IN THE LIGHT OF RECENT EXPERIMENTAL RESULTS
}

\author{
F. Haessner
}

\section{- To cite this version:}

F. Haessner. SINGLE-PROCESS THEORIES OF GRAIN BOUNDARY MIGRATION IN THE LIGHT OF RECENT EXPERIMENTAL RESULTS. Journal de Physique Colloques, 1975, 36 (C4), pp.C4-345-C4-354. 10.1051/jphyscol:1975435 . jpa-00216341

\section{HAL Id: jpa-00216341 https://hal.science/jpa-00216341}

Submitted on 1 Jan 1975

HAL is a multi-disciplinary open access archive for the deposit and dissemination of scientific research documents, whether they are published or not. The documents may come from teaching and research institutions in France or abroad, or from public or private research centers.
L'archive ouverte pluridisciplinaire HAL, est destinée au dépôt et à la diffusion de documents scientifiques de niveau recherche, publiés ou non, émanant des établissements d'enseignement et de recherche français ou étrangers, des laboratoires publics ou privés. 


\title{
SINGLE-PROCESS THEORIES OF GRAIN BOUNDARY MIGRATION IN THE LIGHT OF RECENT EXPERIMENTAL RESULTS
}

\author{
F. HAESSNER
}

\author{
Institut für Werkstoffkunde und Herstellungsverfahren, \\ Technische Universität, Braunschweig, Germany
}

\begin{abstract}
Résumé. - Il faut connaître la structure atomique et électronique des joints de grains pour discuter, d'un point de vue théorique, les mécanismes associés à la migration des joints de grains activée thermiquement.

En ce qui concerne la structure atomique, beaucoup d'informations nouvelles furent acquises ces dernières années (les travaux présentés à ce colloque en témoignent); mais ces informations ne peuvent qu'étendre qualitativement les concepts heuristiques existants (dans certains cas déjà bien anciens) des mécanismes de migration intergranulaire.

Par contre, l'effet de la structure électronique des joints de grains n'a pas été du tout considérée jusqu'à présent. L'idée que cet aspect est également important, est assez nouvelle.

A cause de cela, et puisqu'il existe déjà de nombreux articles de revue sur la migration des joints de grains, cet exposé-ci est limité essentiellement à la discussion de quelques questions restées sans réponse, importantes pour l'interprétation théorique de la migration des joints de grains, spécialement dans les métaux de haute pureté. Seul le cas des joints de grand angle est traité ; l'effet des différences d'orientation sera discuté dans d'autres communications.

Abstract. - Theoretical treatment of the mechanisms associated with thermally activated grain boundary migration requires a knowledge of the atomistic and electronic structure of the grain boundary. Although in recent years a whole range of new data has been acquired concerning the atomistic structure of grain boundaries (see for example the relevant papers presented at this colloquium) they can do no more than qualitatively extend the existing, in some cases really old, heuristic concepts of grain boundary migration mechanisms. The effect of the electronic structure on grain boundary migration has not been considered at all till now. The idea that this aspect also is of importance is rather new.

In view of this, and considering that there are already a number of recent review articles on the subject of grain boundary migration [1-4], the present paper is restricted essentially to the discussion of several unanswered questions which are of general importance for a deeper theoretical understanding of grain boundary migration in very pure metals. The discussion is also restricted to large angle grain boundaries. Orientation effects will not be included because they are discussed in another of the papers to be presented.
\end{abstract}

1. Current theories. - The theories are divided into single process and group process according to the assumed method of material transport which effects the displacement of the grain boundary [1]. In single process theories it is assumed that the elementary process depends on the uncorrelated release or deposition of individual atoms from the lattice and on to the lattice of the neighbouring grain. The rate of grain boundary migration has been calculated many times on this basis of this theory $[1,5]$. The individual treatments differ only in the way in which the overall process is split into individual stages. In the group process theories it is assumed that a group of atoms change from one lattice to the other in a thermally activated event. Here again various explicit formulations exist for the rate of grain boundary migration [1].

In the past, interest has centred primarily on single process theories because it was considered that they would yield better agreement with experimental data for grain boundary migration in very pure metals than group process theories $[1,2,6]$. In spite of the success of the single process theories, several fundamental questions have still not been answered completely or have been provoked again by more recent experimental observations.

Single process theories yield an expression for the rate of migration of a boundary of the form

$$
V=v b \varphi \cdot \frac{p}{K T} \exp \frac{\Delta S}{K} \cdot \exp -\frac{\Delta H}{K T}
$$

in which $b$ is the atomic diameter, $\nu$ the effective attack frequency, $p$ the driving force (energy per atom), $\Delta S$ and $\Delta H$ the activation entropy and enthalpy and $\varphi(<1)$ a more or less complicated function, which depends basically on the assumed transport model and hence in the last analysis on the assumptions made about the structure of the system lattice $\alpha-$ grain boundary - lattice $\beta$. For example in the ledge model due to Gleiter [7], $\varphi$ is related to the step density on the grain surfaces, and in the models of In der Schmitten, Haasen and Haessner [8] and of Haessner and Hofmann [5] $\varphi$ depends, among other things, on the concentration 
of vacancies in the boundary. $\varphi$ also depends on the assumed thickness of the grain boundary [2].

Equation (1) can be written formally

$$
V=m \cdot p
$$

where $m$ is the mobility. The conceptual division of the velocity into a mobility (of the boundary) and a driving force acting on the boundary according to (2), which is almost always made in the analysis of experimental data [9], implies that $m$ and $p$ are independent variables of the existing system. Since, however, both quantities depend on the structural characteristics of the system (lattice $\alpha-$ grain boundary - lattice $\beta$ ) this independence is to be expected theoretically only in very special cases. The validity of (2) should therefore be tested in each individual case before far reaching conclusions are drawn from a mobility derived from the experimental data. This caution should be exercised at least in all experiments in which the driving force depends on differences in the defect concentration in the grains under consideration (e. g. different dislocation densities ( ${ }^{1}$ ), substructures or vacancy concentrations). However, even in cases in which the shape or curvature of the grain boundary changes continually as it migrates, a simultaneous change in $\varphi$ with $p$ cannot $a$ priori be excluded.

The situation is better defined as regards mobility and driving force when a plane boundary migrates between two grains in which the free energy is continuously and homogeneously distributed over a larger volume. An example of this is a bicrystal of a material exhibiting anisotropic magnetic behaviour in a magnetic field [10]. The driving forces so obtained are however so small [11] that this theoretically promising approach has as yet met with little success. It is thus still necessary to rely on the theoreticaly unsatisfactory driving forces discussed above for obtaining velocity data.

Other conditions being constant (1) the temperature dependence of the grain boundary velocity obeys an Arrhenius expression

$$
V=V_{0} \exp -\frac{\Delta H}{K T}
$$

where $V_{0}$ is the pre-exponential factor. At present it is not possible to make predictions about $\Delta H$ from first principles. Since the validity of (3) has been confirmed experimentally many times in the past then, based on the empirically determined temperature dependence, the activation enthalpy $\Delta H$ is usually taken to be similar to that of grain boundary self diffusion $Q$.

If a diffusion constant is formally defined

$D_{\mathrm{m}}=D_{\mathrm{m} 0} \exp -\frac{Q}{K T}=v b^{2} \exp \frac{\Delta S}{K} \cdot \exp -\frac{Q}{K T}$

(1) In ref [7] a case is considered which leads theoretically to $V \propto p^{2}$. the boundary velocity can be expressed as

$V=\frac{D_{\mathrm{m}}}{b} \cdot \frac{p}{K T} \cdot \varphi=\frac{D_{\mathrm{m} 0}}{b} \cdot \frac{p}{K T} \varphi \cdot \exp -\frac{Q}{K T}$.

The gross concept of the activation enthalpy mentioned above is extremely unsatisfactory for several reasons. On the one hand it is known that the magnitude of $\Delta H$ resp. $Q$ depends on the structural features of the system [1] $\left(^{2}\right)$. On the other, several recent observations have shown that even when the macroscopic geometrical parameters of the lattice $\alpha$ - grain boundary - lattice $\beta$ system are held constant, the activation enthalpy is constant only within certain definite ranges of temperature $[12,13]$. Finally, the function $\varphi$ can depend on temperature, for example when the vacancy concentration in the boundary can be considered an essential factor for boundary movement [1].

Within the framework of the single process theories an upper limit can be given for the pre-exponential factor $V_{0}$ which cannot in principle be exceeded. This maximum value obtains if it is assumed that each atom at the surface of the grain can change from one lattice to the other in a single step if the thermal activated state characterised by $\Delta H$ is reached. In this extreme case the function $\varphi=1$. If the Debye limiting frequency $\nu_{D}$ $\left(\simeq 10^{13} \mathrm{~s}^{-1}\right.$ ) is substituted for the effective attack frequency, equations (1) and (5) yield

$$
\begin{aligned}
& V_{0}^{\max } \simeq v_{\mathrm{D}} \cdot b \cdot \exp \frac{\Delta S}{K} \cdot \frac{p}{K T} \\
& V_{0}^{\max } \simeq \frac{D_{\mathrm{m} 0}}{b} \cdot \frac{p}{K T} .
\end{aligned}
$$

An upper limit can be estimated for the activation entropy in (6) based on the magnitude of the entropy of fusion. In the case of metals its value is of the order of $2 . K$.

By comparing experimentally determined preexponential factors $\left(V_{0}\right)$ with $V_{0}^{\max }$ values it is possible to test the fundamental assumptions of the single process theories in as much as the $V_{0}$ values should always be considerably smaller than $V_{0}^{\text {max. }}$. A number of difficulties arise when such a comparison is attempted. Since measurements are almost always made at one driving force only, the validity of (2) cannot be checked. Furthermore the exact size of the effective driving force is frequently not known. It may have been measured roughly, or, more commonly, only more or less indirectly determined. Finally, the numerical value of $V_{0}$ depends sensitively on the size of the activation enthalpy. Since only very small amounts of dissolved impurity atoms can increase the activation

(2) $\Delta H$ and $Q$ very probably depend in a different way on the structural features. 
enthalpy hence yielding a value of $V_{0}$ which is too large compared with that for the pure metal, there is a danger that spurious experimental data, i. e. those which do not at all correspond to the pure metal, could be used for the comparison [5, 11].

In the past, discrepancies between theoretical predictions and experimental data for pre-exponential factors were happily ascribed to the effect of impurity atoms, for example in the frame of the impurity-drag theory $[2,11,14]$. One way out of this difficulty is to use only those experimental values for which the activation enthalpy was very small, say about the value for grain boundary self diffusion. Then, according to present notions, and for the temperature range under discussion, we really have the case of the pure metal.

If the function $\varphi$ in (1) and (5) can be expressed explicitly only under certain assumptions, then in qualitative terms it is to be expected that, other factors being constant, the size of $\varphi$ will increase with the transparency of the boundary. This is the basis for the supposition that the migration velocity increases with increasing porosity i, e. vacancy concentration in the boundary. Experimental evidence for this has long been available [1]. All model-based considerations of the effect of vacancies assume that diffusion jumps giving rise to grain boundary displacements are possible only by processes in which atoms change place with vacancies $[5,7,8]$. According to the model used, the dependence of the velocity on the vacancy concentration at any given moment is given by

$$
V \propto \frac{c_{\mathrm{m}}}{1+A c_{\mathrm{m}}} \quad \text { (7) resp. } V \propto \frac{c_{\mathrm{m}}^{2}}{1+B c_{\mathrm{m}}}
$$

( $A$ and $B$ are parameters dependent on the model). In (7) $A c_{\mathrm{m}}$ 《 1 whereas in (7a) $B c_{\mathrm{m}}$ can be both «1 and " 1 . According to these models the weakest and strongest vacancy dependence is $V \propto c_{\mathrm{m}}$ and $V \propto c_{\mathrm{m}}^{2}$ respectively.

Since, however, a migrating grain boundary is continually accepting and giving up vacancies from and to the two adjacent lattices it can be expected that in the general case $c_{\mathrm{m}}$ is a function of time and grain boundary velocity (presumably tending to a limiting value $C_{\mathrm{L}}$ ) [8]. This can lead to a very complex relationship between the velocity and the temperature and driving force [15]. The quantitative treatment of the effect of vacancies is, furthermore, very complex since assumptions about vacancy sources and sinks must be made. Since in any individual case the sources and sinks can be quite different $[16,17]$, statements which are capable of being generalized cannot be made at present. The functions given in (7) and (7a) should thus be regarded with a certain degree of caution.

2. Discussion of the experimental data. 2.1 GENERAL CONSIDERATIONS. - Experimental data relating to the rate of grain boundary migration can be obtained in two ways. Either the displacement of an individual boundary or the mean value of the grain size of a number of grains is measured as a function of annealing time. The advantages and disadvantages of both methods have been discussed exhaustively on numerous occasions $[1,3,18]$. The data obtained for individual boundaries are fundamentally more suitable for quantitative analysis than the mean value data because in the first case the structural parameters are better defined and the effects of changes in driving force and mobility with time on the velocity can be estimated more readily. Furthermore in the case of the mean value measurements it is necessary to take into account the rather indefinable influence of the grain morphology and orientation distribution of the grains on the mean grain size. This means that a discussion of the pure experimental data can only be very vague and at best extremely difficult $[9,19]$. In the following paragraphs, therefore, the discussion is restricted mainly to data obtained from individual boundaries.

Although many measurements on individual boundaries are cited in the literature, very few of them can be used to elucidate the questions under discussion here because most of them were made on metals of inferior purity. A critical discussion of the experimental data available up to about 1971 from the point of view of purity has been published by Luicke, Rixen and Rosenbaum [2]. In the following, therefore, only the results on aluminium [20-23] analysed in this publication will be considered together with other, in some cases more recent, data on aluminium [24], copper [25, 26], nickel [27], lead [28, 29] and gold [30] for which it can be assumed, thanks to the low value of the activation enthalpy, that the results are not falsified by the presence of impurity atoms.

The choice of experimental data is further limited by the absence in many cases of information concerning the size of the driving force. The experimental data satisfying the stated criteria are collected in table $\mathbf{I}$.

2.2 DEPENDENCE OF THE VELOCITY ON THE DRIVING FORCE. - Up to now the only measurements of the velocity of a single large angle grain boundary over a wide range of driving forces are those made by Viswanathan and Bauer [25] on an $18^{\circ}[100]$ tilt boundary in copper. They were able to demonstrate a proportionality between $V$ and $p$ for this boundary in the driving force range $4 \times 10^{-3}$ to $1.6 \times 10^{-1} \mathrm{cal} / \mathrm{mol}$. Since the curvature of the boundary decreased continuously throughout the experiment it follows that the effect of curvature on the mobility $m$ (or the function $\varphi$ ) is negligibly small (3).

(3) This removes the objection that the relationship $V \alpha p^{55}$ established by Rath and Hu [31] in a wedge-bicrystal experiment on aluminium is spurious because the mobility is not constant bout a function of the curvature. 
TABLE I

Experimental data collected from literature on motion of single boundaries

\begin{tabular}{|c|c|c|c|c|c|c|c|}
\hline No. & Ref. & Material & $\begin{array}{l}\text { Driving force } \\
{[\mathrm{cal} / \mathrm{mol}]}\end{array}$ & $\begin{array}{c}\text { Activation } \\
\text { enthalpy } \Delta H \\
{[\mathrm{kcal} / \mathrm{mol}]}\end{array}$ & $\begin{array}{l}\text { Preexponential } \\
\text { factor } V_{0} \\
{[\mathrm{~cm} / \mathrm{s}]}\end{array}$ & $\begin{array}{c}\text { Temperature } \\
\text { range } \\
{[\mathrm{K}]}\end{array}$ & Type of experiment \\
\hline - & - & - & - & - & - & - & - \\
\hline 1 & {$[21]$} & $\mathrm{Al}$ & 4 & 15.0 & $2 \times 10^{6}$ & 273-349 & \multirow{3}{*}{$\begin{array}{l}\text { Growth of single grains into rolled } \\
\text { polycrystal }\end{array}$} \\
\hline 2 & [20] & Al & 28 & 13.1 & $\begin{array}{r}8 \times 10^{5} \\
55 \times 10^{5}\end{array}$ & $236-287$ & \\
\hline & [24] & Al & 28 & 11.9 & & $230-340$ & \\
\hline 4 & {$[22]$} & $\mathrm{Al}$ & 1 & 16.0 & $4.8 \times 10^{5}$ & $303-343$ & $\begin{array}{l}\text { Growth of single grains into rolled } \\
\text { single crystal }\end{array}$ \\
\hline 5 & [23] & $\mathrm{Al}$ & $2 \times 10^{-3}$ & 13.0 & 1.6 & $833-913$ & $\begin{array}{l}\text { Growth of perfect grains into crysta } \\
\text { with striation substructure }\end{array}$ \\
\hline 6 & {$[25]$} & $\mathrm{Cu}$ & $\begin{array}{l}4.9 \times 10^{-3} \\
1.6 \times 10^{-1}\end{array}$ & 29.4 & $\begin{array}{l}2.4 \times 10^{2} \\
1.1 \times 10^{4}\end{array}$ & 698-973 & $\begin{array}{l}\text { Motion of hyperbolalike shaped boun- } \\
\text { dary between two undeformed single } \\
\text { crystals }\end{array}$ \\
\hline 7 & {$[26]$} & $\mathrm{Cu}$ & 13.5 & $\begin{array}{l}26.6 \\
29.0\end{array}$ & $\begin{array}{r}8 \times 10^{7} \\
7.5 \times 10^{8}\end{array}$ & $403-483$ & $\begin{array}{l}\text { Growth of single grains into rolled } \\
\text { single crystal }\end{array}$ \\
\hline 8 & {$[30]$} & $\mathrm{Au}$ & 6.5 & 15.0 & $1.4 \times 10^{3}$ & $383-433$ & $\begin{array}{l}\text { Growth of single grains into rolled } \\
\text { single crystal }\end{array}$ \\
\hline 9 & {$[27]$} & $\mathrm{Ni}$ & 7 & 30.0 & $6 \times 10^{6}$ & $523-673$ & $\begin{array}{l}\text { Growth of single grains into rolled } \\
\text { polycrystal }\end{array}$ \\
\hline 10 & {$[28]$} & $\mathrm{Pb}$ & $1.9 \times 10^{-3}$ & 6.0 & 1.1 & $473-593$ & \multirow{2}{*}{$\begin{array}{l}\text { Growth of perfect grains into crystal } \\
\text { with striation substructure }\end{array}$} \\
\hline 11 & [29] & $\mathrm{Pb}$ & $1.9 \times 10^{-3}$ & 6.1 & 1.8 & $473-593$ & \\
\hline
\end{tabular}

Velocity measurements on aluminium have been made by various authors over a wide range of driving forces. These date (extrapolated to $373 \mathrm{~K}$ corresponding to $0.4 T_{\mathrm{M}}, T_{\mathrm{m}}$ is the absolute melting point) are plotted in figure 1 as a function of the driving force as suggested by Rath and $\mathrm{Hu}$ [31].

This method of representation has been used in the past to assess whether the grain bundary was free of or loaded by impurity atoms [2, 31, 32]. It was thereby assumed that for the impurity-free boundary $V \propto p$. If this assumption is correct it can be concluded that in the measurements on aluminium only Frois and Dimitrov [20], Fromageau [24], and Gordon and Vandermeer [21] were dealing with impurity free boundaries.

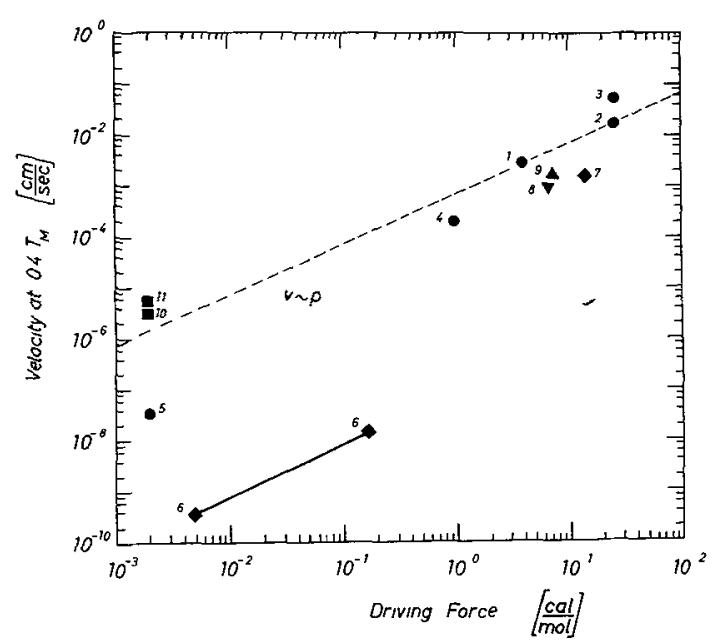

FiG. 1. - Dependence of grain boundary velocity on driving force as observed by several authors (Extrapolated or interpolated to $0.4 . T_{\mathrm{M}} ; T_{\mathrm{M}}$ absolute melting temperature. Numbers see Table I) (After réf. [31]).

Conversely the few points in figure 1 are not a critical indication of the real extent of the proportionality between $v$ and $p$ in aluminium over a large range of driving forces. There is merely a good probability that it exists for the three measurements just mentioned.

The other measurements contained in table I (extrapolated to $0.4 T_{\mathrm{M}}$ ) are also plotted in figure 1 . The measurements of Viswanathan and Bauer [25] naturally lie on the straight line $V \propto p$. In the case of data from Aust and Rutter [28, 29] on lead, from Detert and Dressler [27] on nickel, from Haessner and Holzer [26] on copper and from Altenmüller and Hofmann [30] on gold the measurements were made at one driving force only. The fact that the extrapolated velocities in lead are close to the straight line $V \propto p$ for aluminium is probably coincidental. The fact that the single value for copper (no. 7) shows no correspondence with the copper curve due to Viswanathan and Bauer might be explained by the different experimental procedure which have been used by both groups of authors: Viswanathan and Bauer have studied an $18^{\circ}[100]$ tilt boundary whereas Haessner and Holzer made their measurements on the fastest moving boundaries. The data on nickel and gold also have been gained on fastest moving boundaries.

Summarising, it turns out that there has been only one satisfactory experimental demonstration of the proportionality between $v$ and $p$ up to now [25]. The structural conditions under which this simple relationship holds true for large angle grain boundaries in pure metals remain obscure. Thus all analyses of experimental data based on 
equation (2) still contain an indefinable element of uncertainty.

2.3. COMPARISON OF THE MAXIMUM POSSIBLE PRE-EXPONENTIAL FACTORS ( $V_{0}^{\max }$ ) WITH EXPERIMENTAL VALUES $V_{0}$. - The data contained in table I were used to determine $V_{0}^{\max }$ according to (6). The results of nos. 4 and 5 were not used because in these two cases the proportionality between $V$ and $p$ is obscure. The average value of the temperature interval under consideration in each case was used for the temperature and the values $10^{13} \mathrm{~s}^{-1}$ and $2 . k$ for $v_{\mathrm{D}}$ and $\Delta S$ respectively. In figure 2 these data are compared with experimental values $V_{0}$ contained in table $I$.

Figure 2 shows that with the exception of the results on gold and lead all other experimentally determined pre-exponential factors are larger than the maximum possible according to the single process theory $\left({ }^{4}\right)$. This statement remains essentially correct even when it is taken into account that the experimental values $V_{0}$ are only accurate to one order of magnitude. The scatter shown in figure 2 represents this uncertainty. It is calculated under the assumption that the activation enthalpies given in table $I$ are accurate to $\pm 10 \%\left({ }^{5}\right)$.

Figure 3 shows the analogous comparison of the $V_{0}$ and $V_{0}^{\max }$ values according to $(6 \mathrm{a})$. The necessary $D_{\mathrm{m} 0}$ values were either estimated from lattice self diffusion data according to $D_{\mathrm{m} 0} \simeq 10^{-2} D_{\mathrm{m} 0}$

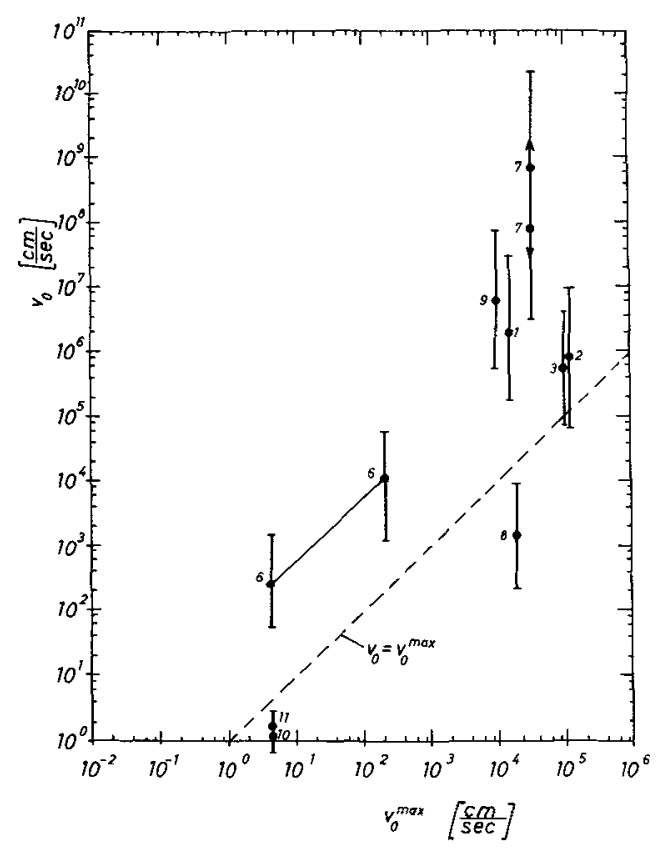

FIG. 2. - Correlation between experimental values of the preexponential factor $V_{0}$ and the maximum theoretical value $V^{\max }$ according to eq. [6]. (Data from Table I ; cf. text).

(4) In ref. [25] $\Delta S \simeq 7 . k$. In this extreme case $V_{0} \approx V_{0}^{\max }$. The present author, however, feel that such a high size of the activation entropy is difficult to justify.

(5) The uncertainty in the values of the driving force is of no significance and was therefore neglected.

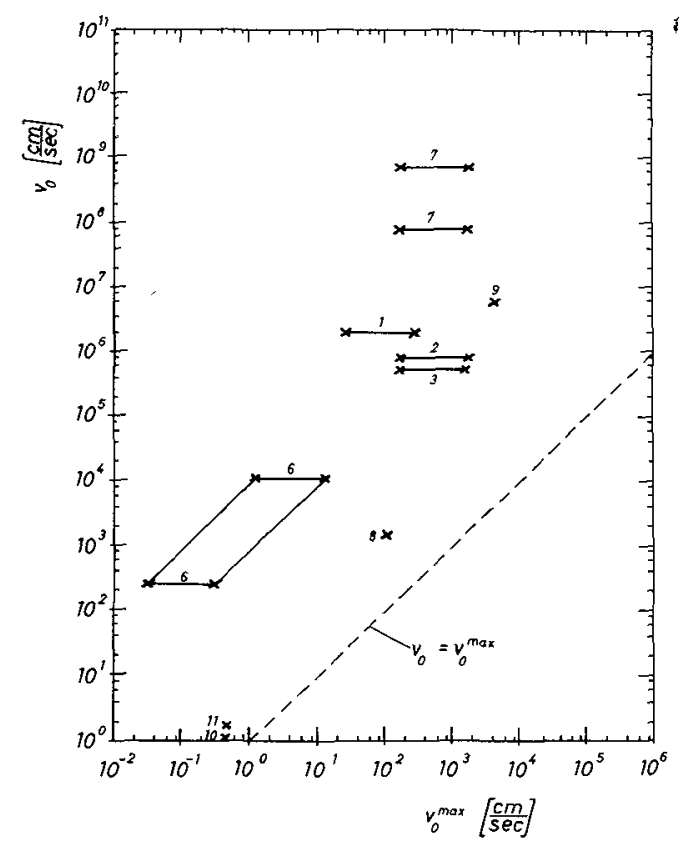

FIG. 3. - Correlation between experimental values of the preexponential factor $V_{0}$ and the maximum theoretical value $V^{\max }$ according to eq. (6a). (Data from table I ; cf. text ; used diffusion data: $\mathrm{Al}$ réf. $[38], \mathrm{Cu}$ réf. $[39,40], \mathrm{Au}$ réf. $[41,42], \mathrm{Ni}$ réf. [43, 44], $\mathrm{Pb}$ réf. [45].)

lattice [33-37] or experimentally determined $D_{\text {mu }}$ values of grain boundary self-diffusion were used $\left(^{6}\right)$.

For the sake of clarity the scatter for the $V_{0}$ values is not marked in figure 3 . Similar as in figure 2 all $V_{0}$ values are larger than the $V_{0}^{\max }$ values.

The information contained in figures 2 and 3 can be viewed from various standpoints. Either the discrepancy between theoretical prediction and experimental data is a result of inadequate purity of the material, or of insufficient experimental accuracy or of the fundamental value of $\nu_{\mathrm{D}}$ being too small $[2,6,32]$, or the discrepancies are to be taken seriously and attributed to correlated as well as uncorrelated atomic movements contributing to grain boundary migration [5]. A claim that the material purity was inadequate is not likely to be justified in the present case because the preexponential factors were high in spite of a very low activation enthalpy. As regards the other objections it should be noted that taking into account the scatter and choosing a value of $\nu_{\mathrm{D}} \approx 10^{14} \mathrm{~s}^{-1}$ an agreement between $V_{0}$ and $V_{0}^{\max }$ can be reached. This is however no great achievement, since the value of $V_{0}$ should be very much smaller than $V_{0}^{\max }$. This follows simply from the fact that vacancies increase the velocity of migration without any

$\left.{ }^{6}\right)$ The identification of $D_{\mathrm{mo}}$ with lattice or grained boundary self diffusion data is purely an ad-hoc assumption. This procedure is justified mainly in that it is thus possible to compare $V_{0}$ values with other experimental data on single jumps. 
noticeable effect on the driving force or activation enthalpy [1, 8, 26]. Assuming proportionality between velocity and driving force which has only really been demonstrated with Viswanathan and Bauer's data for copper, then in our opinion, figures 2 and 3 show that the single process theory yields $V_{0}^{\max }$ values that are too small.

Much larger pre-exponential factors than those obtained from (6) can be justified if the elementary process of grain boundary migration depends on correlated movement of atoms of such a type that the activation of a single atom leads to the transfer of a whole group of atoms to the orientation of the other crystal. This activation must not necessarily extend to all the atoms of the group as suggested in the first group process theory of Mott [46]. The atomic configurations in grain boundaries calculated by Johanneson and Thölen [47], Gleiter and co-workers [48-50] and others show that such correlated atomic movement is not purely hypothetical. The topological features of these configurations can in certain cases be described by structural groups of associated atoms. The reorientation of these would correspond to the required correlated movement and would effect a simultaneous displacement of the grain boundary.

Very recently the existence of correlated transference processes has been demonstrated experimentally in grain boundary migration by Gleiter and co-workers [51] also on a real system. This will be discussed again in the last section in connection with other phenomena observed at grain boundaries which permit certain general conclusions to be drawn regarding grain boundary structure.

2.4. THE DEPENDENCE OF THE VELOCITY ON VACANCIES. - The quantitative determination of the relationship $V=V(c)$ ( $c=$ vacancy concentration in the grain boundary) meets with difficulties because there is no technique for measuring the quantity $c$ directly. A more or less indirect determination of $c$ has therefore to suffice.

In the only quantitative investigation of this problem by Haessner and Holzer [26], who followed the migration of individual boundaries in neutron-irradiated, deformed copper single crystals, it was observed that the velocity of a boundary increases with increasing neutron dose $n$. Figure 4 shows an increase in the relative velocity $V(n) / V(0)$ dependent on the neutron dose. This effect cannot depend on an increase in driving force as a result of neutron irradiation because a calorimetric measurement shows that the stored energy (and hence the driving force) has not changed significantly. Since Frank vacancy loops form in the matrix as a result of neutron bombardment, the effect is probably caused by radiation-induced athermal vacancies streaming from the matrix into the moving boundary. On the basis of this assumption the radiationdependent additional stationary vacancy concentra- tion $C_{\mathrm{I}}(n)$ in the boundary can be estimated with the aid of the size distribution for Frank vacancy loops measured for different neutron doses [52, 53]. The relationship between $V(n) / V(0)$ and $C_{I}(n)$

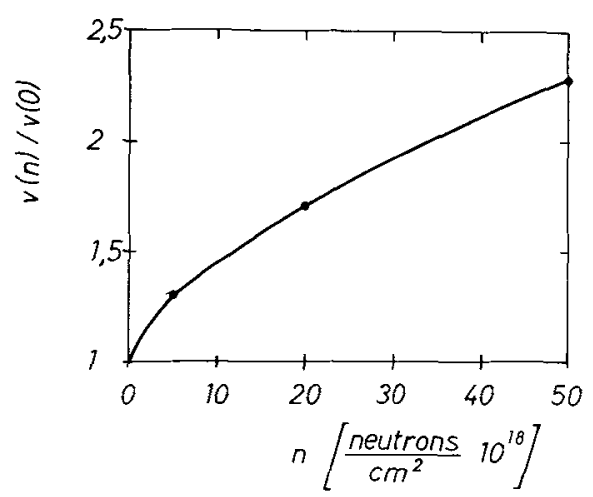

FIG. 4. - Dependence of reduced growth rate in copper on irradiation with fast neutrons.

determined in this way is shown in figure 5. Since the stationary total vacancy concentration $C_{\mathrm{L}}$ is given by $C_{\mathrm{L}}=C_{0}+C_{\mathrm{I}}(n)$ where $C_{0}$ is the concentration of thermal and structural vacancies in the boundary, the relationship $V=V\left(C_{\mathrm{L}}\right)$ can be deduced from figure 5 . The shape of the curve in figure 5 corresponds very well to the relationship

$$
\frac{V(n)}{V(0)}=\left(\frac{C_{1}}{C_{0}}\right)^{2}
$$

with $C_{0}=3.7 \times 10^{11} \mathrm{~cm}^{-2}$ (vacancies per $\mathrm{cm}^{2}$ grain boundary area).

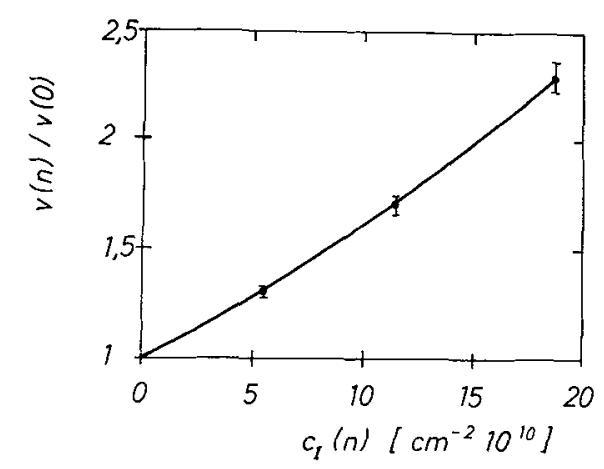

Fig. 5. - Dependence of reduced growth rate in copper on the effective areal density of irradiation-induced vacancies.

If one accepts the basic model in principle, the most critical stage in the analysis is the derivation of the quantity $C_{\mathrm{I}}(n)$ from the measured size distributions of the Frank vacancy loops. Excessive importance should therefore, and since rather few experimental values are available, not be attached to the information contained in the relationship $V\left(C_{\mathrm{L}}\right) \propto C_{\mathrm{L}}^{2}$.

A further experimental technique for studying the 
influence of vacancies which yields information more directly and comprehensibly is to trace the movement of a grain boundary in a deformed single crystal matrix containing small stacking fault tetrahedra. Since stacking fault tetrahedra are stable and immobile up to relatively high temperatures, since their size can readily be adjusted and since they can easily be recognised in the electron microscope, integral measurements of grain boundary velocity could be accompanied by microscopic observations of the way in which a grain boundary reacts with individual stacking fault tetrahedra of various sizes. A suitable metal for such investigations would be gold because stacking fault tetrahedra can be produced in this metal after deformation by electron bombardment at low temperatures [54].

2.5. QUALITATIVE OBSERVATIONS IN CONNECTION WITH THE MOVEMENT OF GRAIN BOUNDARIES. - Several recent observations will be discussed in this section which permit conclusions to be drawn about the relevance of the simple concepts of grain boundary structure which form the basis of the single process theories. Since a material which is homogeneous on a microscopic scale is always assumed in all theoretical treatments of grain boundary motion, a few experimental results and thoughts on this general complex of questions will be presented briefly also.

One of the most important assumptions made in these theories is that the transport process for the release and deposition of atoms from and on to the lattice is statistically uniform overall. The observation discussed above that the activation enthalpy in lead and copper is constant only within certain ranges of temperature, a phenomenon which is attributed to a possible transformation in the boundary structure at a given temperature $[55,56]$, arouses the suspicion that grain boundary structure is subject to strong localised variations. This would mean different transport mechanisms at various points. The most recent observations of Gleiter and co-workers [51] using electron microscopy, who have traced in nickel-aluminium alloys the rearrangement of small ordered atomic groups on transference through the grain boundary, show that the rearrangement can take place quite differently from place to place on the same boundary. Thus regions in which the transference is uncorrelated appear to lie directly adjacent to points at which transference is correlated. The supposition that the transference process may happen in a correlated way is further suggested by the following observation : the elder data of Aust and co-workers on bicrystals [1] of various metals as well as the more recent observations of Bauer and Viswanathan [25, 57] on copper all result in $\ln m$ versus $1 / T$ curves which yield mobility values $m_{0}=m(1 / T \rightarrow 0)$ which are different by orders of magnitude for different types of boundaries. If the activation entropy of the process would be the same for all boundaries this observation is difficult to unterstand.

The results of Pumphrey and Gleiter [58, 59], who followed the spreading of dislocations in the grain boundaries of various metals and alloys using electron microscopy, point in the same direction, namely that the grain boundary properties controlling the passage of atoms depend on many, as yet unknown parameters. According to the authors the velocity of spreading depends strongly on the orientation parameters and vacancy concentration. From this it can be concluded qualitatively that atomic movements taking place along the grain boundary are considerably facilitated by the presence of vacancies. Thus the thickness of the boundary substituted in the function $\varphi$ (eq. 1) does not have to be identical with the geometric thickness of a boundary but can be considerably larger.

The energy of grain boundaries and hence in the last analysis the grain boundary structure has recently been investigated by Gleiter and coworkers [60] using the rotation of single crystal spheres. From this it appears that two contributions exist, a geometrical term and an electronic term [51, 61]. As the case me be which contribution prevails a distinction can be drawn between geometrical and electronic grain boundaries. Geometrical boundaries are characterised by a good atomic fit at the boundary. They are probably narrow. Electronic boundaries cannot be defined by simple geometrical criteria; they are broad. In the case of electronic boundaries it is justifiable to talk of grain boundary vacancies, for geometrical boundaries it is not $\left(^{7}\right)$. A further investigation, which demonstrates the significance of the electronic structure of the grain boundary for its movement, a significance hitherto unknown and completely ignored, has been made by Haessner, Hofmann and Seekel [64]. These authors measured the effect of high direct electric current densities on grain boundary migration in rolled gold single crystals. They found an increase or a decrease in the grain boundary velocity when the boundary was moving towards the cathode or anode respectively as compared with the velocity in the absence of a current. The effect is much larger than would be expected on the basis of a change in driving force as a result of electrotransport assuming a linear relationship beween velocity and driving force.

All these observations show that there are many more aspects to grain boundary mobility than have hitherto been recognised. It is therefore not surprising that a quantitative analysis of experimental grain boundary migration data based on simple

(7) The boundary thickness treated here is not identical with the range of influence of a grain boundary which is important in the impurity-drag theory on account of grain boundary segregation. This range of influence is also of an electronic nature, it can extend far into the lattice $[62,63]$. 
single process theories does not yield a selfconsistent picture.

In the present discussion of the velocity data, a material which is homogeneous on a microscopic scale was always assumed. Naturally, this is not the case. The question is, under what conditions do microscopic inhomogeneities seriously affect grain boundary motion? The most extreme consequence of these inhomogeneities would be jerky motion of a grain boundary. This phenomenon is well known in the case of motion of dislocations. Previously, jerky motion of grain boundaries could always be traced back to trivial effects such as surface grooving, pinning by second phases, and the like. The question as to whether jerky motion also occurs inside a pure metal is still unanswered. If such a phenomenon exists, the easiest proof ought to be obtained at low driving forces. The difference between the true grain boundary velocity and the macroscopically measured mean velocity resulting from the intervals between jerks would have to become smaller with increasing driving forces.

It is always to be expected that with increasing degree of purity, the residual impurity atoms are more and more segregated at lattice defects [65]. Hence at low impurity concentrations of some 10 appm grain boundary enrichment factors of $10^{4}$ or even larger can appear [66]. It is particularly in the case of grain boundary motion that the kind of heat treatment - single anneal, multi anneal strongly affects the kinetics of grain coarsening in high-purity metals [67-70]. Even though a wholly consistent explanation for this cannot yet be given $[2,70]$, one of the causes ought to be the inhomogeneous distribution of impurity atoms. Since the pure metal that is the simplest limiting case for the theory of grain boundary motion, the question arises as to when it is reasonable to speak of impurity atom-free boundaries in a high-purity metal [32, 71-73].

All other macroscopic conditions such as orientation, grain morphology, kind and degree of deformation being the same, the magnitude of the driving force is also undoubtedly affected as a result of the interaction between (residual) impurity atoms and lattice defects. Recent micro-calorimetric investigations by Haessner and Hoschek [74] on doped and deformed copper single crystals show for instance that, depending on the kind of added element, there is a decrease or increase in stored energy $\left({ }^{8}\right)$. The magnitude of these effects is difficult to understand when the distribution of impurity atoms is homogeneous.

Finally, it should be said that the whole area of material homogeneity, and especially the question of the local impurity atom distribution in highpurity metals and the effect of this distribution on grain boundary motion is presently unexplained for the most part. The methods of local trace analysis developed in the past few years should, in principle, be useful in providing more detailed information on this question $[76,77]$; the research activity in this field is very intensive [78-80].

3. Conclusions. - Apart from orientation effects, the migration of large angle grain boundaries in pure metals raises the following questions of fundamental importance for an understanding of the theoretical principles : Under what conditions is the velocity proportional to the driving force? Is grain boundary migration based essentially on one thermally activated process? Under what conditions is the transfer of atoms from one lattice to the other uncorrelated or correlated ? What is the relationship between velocity and vacancies? Under what conditions do impurities and material inhomogeneities affect grain boundary motion?

In addition to classical experiments in which the displacement of the grain boundary is traced quantitatively under the most straight forward conditions possible as a function of only one parameter, other investigatory methods should be used in the elucidation of these questions which yield qualitative results in the sense of a Yes-No decision for the existence of assumed transport mechanisms based on specific grain boundary models. These preferentially include electron microscopy, X-ray techniques, methods of local trace analysis and microcalorimetry on very pure and accurately doped metals with different impurity atom distributions.

Acknowledgement. - The author is indebted to Prof. H. Gleiter and Dr. S. Hofmann for making available unpublished results and for stimulating and critical discussions.

$\left({ }^{8}\right)$ The stored energy [75] is not a priori identical with the effective driving force in grain boundary motion because of the occurrence of drag effects but the stored energy does represent on upper limit.

\section{References}

[1] Gleiter, H. and Chalmers, B., «High-Angle Grain Boundaries " in Progress in Materials Science. Editors : B. Chalmers, J. W. Christian and T. B. Massalski (Pergamon Press) 1972, vol 16, p. 127

[2] LUCKE, K., RIXEN, R. and Rosenbaum, F. W., «On the Theory of Grain Boundary Motion » in Nature and Behavior of Grain Boundaries. Editor : H. Hu (Plenum Press) 1972, p. 245.
[3] Simpsom, C. J. and Aust, K. T., Surf. Sci. 31 (1972) 479.

[4] Higgins, G. T., Metal Science 8 (1974) 143.

[5] Haessner, F. and Hofmann, S., Z. Metallkd. 62 (1971) 807.

[6] Gordon, P. and VANDERMEer, R. A., "Grain Boundary Migration» in Recrystallization, Grain Growth and Textures. Editor: H. Margolin (ASM, Metals Park, Ohio) 1966 , p. 205.

[7] Gleiter, H., Acta Metall. 17 (1969) 853. 
[8] IN DER SCHMirten, W., HaAsen, P. and HAESSNER, F., $Z$ Metallkd. 51 (1960) 101.

[9] Hu, H., Can. Metall. 13 (1974) 275.

[10] Mullins, W. W., Acta Metall. 4 (1956) 421.

[11] Lucke, K. and Stuwe, H. P., "Grain Boundary Motion » in Recovery and Recrystallization of Metals. Editor: L. Himmel (Interscience Publ.) 1963, p. 171

[12] Simpson, C. J., Aust, K. T., and Winegard, W. C., Met. Trans. 2 (1971) 987, 993.

[13] Grewe, H. G., SCHMidT, P. F. and SchUR, K., Z. Metallkd. 64 (1973) 502.

[14] CAHN, J. W., Acta Metall. 10 (1962) 789

[15] Grewe, H. G., Private Communication.

[16] Gleiter, H., Acta Phys. Austriaca 35 (1972) 64

[17] Gleiter, H., J. Less-Common Metals 28 (1972) 297.

[18] AusT, K. T., In Interfaces Conference, Melbourne. Editor : R. C. Gifkins (Butterworths) 1969, p. 307.

[19] Rhines, F. N. and CraIG, K. R., Met. Trans. 5 (1974) 413.

[20] Frois, C., and Dimitrov, O., Ann. Chim. 1 (1966) 113.

[21] Gordon, P. and VAndermeer, R. A., Trans. AIME 224 (1962) 917.

[22] RaTH, B. B. and HU, H., Trans AIME 236 (1966) 1193.

[23] Aust, K. T. and RUTter, J. W., "Some Annealing Phenomena in High-Purity Metals » in Ultra High Purity Metals (ASM, Metals Park, Ohio) 1962, p. 115.

[24] Fromageau, R., Mem. Sci. Rev. Metall. LXVI (1969) 287.

[25] Viswanathan, R. and Bauer, C. L., Acta Metall. 21 (1973) 1099.

[26] Haessner, F. and Holzer, H. P., Acta Metall. 22 (1974) 695.

[27] Detert, K. and Dressler, G., Acta Metall. 13 (1965) 845.

[28] Aust, K. T. and RutTer, J. W., Trans. AIME 215 (1959) 820

[29] Aust, K. T. and Rutter, J. W., Trans. AIME 218 (1960) 682.

[30] Altenmưller, U. and Hofmann, S., Private Communication.

[31] RatH, B. B. and HU, H., Trans. Met. Soc. AIME 245 (1969) 1577

[32] RATH, B. B. and HU, H., "Influence of Solutes on the Mobility of Tilt Boundaries $»$ in Nature and Behavior of Grain Boundaries. Editor : H. Hu (Plenum Press) 1972 , p. 405.

[33] Shewmon, P. G., Diffusion in Solids (McGraw. Hill) 1963.

[34] Turnbull, D. and Hoffman, R. E., Acta Metall. 2 (1954) 419.

[35] Hoffman, R. E., Acta Metall. 4 (1956) 98.

[36] Savirski, A. V., Fiz. Met. Metalloved. 10 (1960) $564 ; 16$ (1963) 886 .

[37] Klotsman, S. M., Timofeyev, A. N. and Trakhtenber, I. SH., Fiz. Met. Metalloved. 16 (1963) 895.

[38] Rosenberg, R. and Beerenbaum, L., Appl. Phys. Lett. 16 (1970) 27.

[39] Bowden, H. G. and Balluffi, R. W., Phil. Mag. 19 (1969) 101.

[40] Krishtal, M. A. et al., Diffuts. Metal. Splovakh (1968) p. 226.

1411 SEEger, A. and MEHrer, H., Phys. Stat. Sol. 29 (1968) 231.

[42] ERMET, U., RUPP, W. and SizMANN, R., International Conference on Vacancies and Interstitials in Metals, Jülich 1968. Vol. 1 p. 30.

[43] Amonenko, V. M., et al., Phys, Met. Metallogr., 27 (1969) 627.

[44] BADIA, M., Doctoral Thesis, Nancy 1969.
[45] Miller, J. W., Phys. Rev. 181 (1969) 1095.

[46] Mотт, N. F., Proc. Phys. Soc. 60 (1948) 391

[47] Johannesson, T. and Thólen, A., Phil. Mag. 21 (1970) 1223.

[48] Weins, M., Chalmers, B., Gleiter, H. and Ashby, M., Scr, Metall. 3 (1969) 601.

[49] Weins, M., Gleiter, H. and Chalmers, B., Scr. Met. 4 (1970) 235.

[50] GLeiter, H., and Lissowski, A., Z. Metallkd. 62 (1971) 237.

[51] Gleiter, H., Private Communication.

[52] RUHLE, M., in Radiation Damage in Reactor Materials. Vol. 1. International Atomic Energy Agency, Vienna 1969.

[53] Rühle, M., Häusermann, H. and RapP, R., Phys. Stat. Sol. 39 (1970) 609.

[54] SCHEIDler, G. P., and ROTH, G., International Conference on Vacancies and Interstitials in Metals, Jülich 1968, Vol. 1 p. 391

[55] GLEITER, H., Z. Metallkd. 61 (1970) 282.

[56] HART, E. W., « Grain Boundary Phase Transformations » in Nature and Behavior of Grain Boundaries. Editor: H. Hu (Plenum Press) 1972, p. 155.

[57] Viswanathan, R., and Bauer, C. L., Metall. Trans. 5 (1974) 1690.

[58] Pumphrey, P. H. and Gleiter, G., Phil. Mag. 30 (1974) 593

[59] Pumphrey, P. H. and Gleiter, H., Submitted to Phil. Mag. [601 Herrmann, G., Sautter, H., Bäro, G. and Gleiter, H., Proc. Fourth Bolton Landing Conf. 2-12. June 1974.

[61] Herrmann, G., Sautrer, H., Baro, G. and Gleiter, H., Scr. Met. 9 (1975) 357.

[62] Klein, H. P. and Gleiter, H., Phil. Mag. 26 (1973) $519 ; 27$ (1973) 1009.

[63] FridmanN, E. M., Kopezky, C. V. and ShVindlerman, L. S., Z. Metallkd. 66 (1975) 533.

[64] HaESSNER, F., HofMANn, S. and SEeKEL, H., Scr. Met. 8 (1974) 299.

[65] Hondros, E. D., Interfaces, Proc. Conf. (Melbourne). Editor: R. C. Gifkins, (Butterworths) 1969, p. 77.

[66] Hondros, E. H., Seah, M. P., Scr. Metall. 6 (1972) 1007.

[67] Droler, J. P. and Galibols, A., Acta Metall. 16 (1968) 1387.

[68] Drolet, J. P., and Galibois, A., Metall. Trans. 2 (1971) 53.

[69] Fiset, M., Braunovic, M. and Galibols, A., Scr. Metall. 5 (1971) 325

[70] Galibois, A., Poliquin, H. and Rath, B. B., Scr. Metall. 8 (1974) 1439.

[71] Hu, H. and RATH, B. B., Metall. Trans. 1 (1970) 3181.

[72] KASEN, M. B., Scr. Metall. 4 (1970) 575.

[73] Kasen, M. B., Phil. Mag. 21 (1970) 599.

[74] Haessner, F. and HoscheK, G., Submitted to Scr. Metall.

[75] Bever, M. B., Holt, D. L. and Titchener, A. L., « The Stored Energy of Cold Work $»$ in Progress in Materials Science. Editors: B. Chalmers, J. W. Christian and T. B. Massalski (Pergamon Press) 1973, vol. 17.

[76] Chang, C. C., Surf. Sci. 24 (1971) 149.

[77] Evans, C. A., Anal. Chem. 44 (13) (1972) 67 A.

[78] Powell, B. D. and MykuRA, H., Acta Metall. 31 (1973) 1151 .

[79] Hoffmann, J., Hofmann, S. and Thlmann, L., Z. Metallkd. 65 (1974) 721

[80] Doig, P., Edington, J. W. and Jacobs, M. H., Phil. Mag., 31 (1975) 285 


\section{DISCUSSION}

O. DIMITROV : You showed that the magnitude of the preexponential factor in the expression of the migration velocity points to the operation of correlated process of atom transfer. You also shawed that vacancy concentration is very important for determining the migration rate. Do not you think that those two pieces of evidence are somewhat contradictory? It would be reasonable to suppose that the vacancy concentration should be important in single process type model, but not so much in the case of a cooperative process.

F. HAESSNER: The influence of vacancies on grain boundary migration very probably depends essentially on the state in which the vacancies exist in the boundary. In the case of single vacancies there are indeed some difficulties in the interpretation. But it seems to me questionable that the vacancies exist in the form of single defects in the boundary. I would not dare to make a supposition if associated vacancies are more effective on single or on group processes, since at present we can make at best only very vague assumptions on the details of possible group processes.

J. BEELER : Concerning Dr. Dimitrov's remark about vacancies not affecting group processes : Our simulations of antiphase boundary and surface behavior show that large vacancy concentrations lead to group processes based on divacancies and trivacancies. This is especially important when impurities are present.

F. HAESSNER : It would be interesting to know if these observations also hold for large angle grain boundaries, especially for boundaries of the $\langle 111\rangle \simeq 30^{\circ}$ tilt type, whish are fast moving boundaries in copper.

D. MC LEAN : Your graph of the incluence of vacancy concentration on rate of migration appears to show remarkable sensitivity since, taken literally the graph indicates on extra vacancy concentration of $\sim 0.01 \%$ increases the rate by $21 / 2 x$. For comparison, the typical vacancy concentration of a grain boundary is $\sim 20 \%$. Is one to suppose that in your experiment the extra grain boundary concentration waz only $0.01 \%$, or that this quantity is multiplied by a large factor?

F. HAEssner: The scale in Fig. 5 does not contain any factor by whish it has to be multiplied. According to Fig. 5 and equ. (7a) the concentration of thermal and structural vacancies, whish are effective with respect to boundary migration in unirradiated $\mathrm{Cu}$, comes out to be $3.7 \times 10^{11} \mathrm{~cm}^{-2}$. An additionnal (irradiation induced) vacancy concentration of $2 \times 10^{11} \mathrm{~cm}^{-2}$ increases the migration velocity roughly by a factor of 2.5 .

If one compares the typical vacancy concentration of a grain boundary $\simeq 20 \%$ with the numbers given here, whish are of the order of some $0.01 \%$, one should be aware of the fact that the first number is an estimate of the whole vacancy content of a boundary at rest, whereas the second number gives an estimate only of the vacancies whish are effective for grain boundary migration.

P. LESBATS : On peut penser que la présence d'un assez grand nombre de lacunes changent les énergies des configurations de structures de joints probables et que ceci modifie le terme préexponentiel : fréquence de saut, entropie.

F. HAESSNER: In principle I agree with your conclusion. To estimate this effect theoretically seems to me to be rather difficult, since we do not know the structural details of a moving boundary. Within the framework of the formalism of reaction rate theory, qualitatively, I would suggest that the attack frequency decreases, whereas the activation entropy increases with increasing vacancy concentration. The experimental determination of grain boundary velocity versus vacancy concentration is not as accurate as to detect such an influence. Hence we did not take into this effect in our analysis on the behavior of vacancies. 